\title{
German Spent Nuclear Fuel Legacy: Characteristics and High-Level Waste Management Issues
}

\author{
A. Schwenk-Ferrero \\ Karlsruhe Institute of Technology (KIT), Hermann-von-Helmholtz-Platz 1, 76344 Eggenstein-Leopoldshafen, Germany \\ Correspondence should be addressed to A. Schwenk-Ferrero; aleksandra.schwenk-ferrero@kit.edu
}

Received 12 October 2012; Revised 2 December 2012; Accepted 6 December 2012

Academic Editor: Alejandro Clausse

Copyright (C) 2013 A. Schwenk-Ferrero. This is an open access article distributed under the Creative Commons Attribution License, which permits unrestricted use, distribution, and reproduction in any medium, provided the original work is properly cited.

\begin{abstract}
Germany is phasing-out the utilization of nuclear energy until 2022. Currently, nine light water reactors of originally nineteen are still connected to the grid. All power plants generate high-level nuclear waste like spent uranium or mixed uranium-plutonium dioxide fuel which has to be properly managed. Moreover, vitrified high-level waste containing minor actinides, fission products, and traces of plutonium reprocessing loses produced by reprocessing facilities has to be disposed of. In the paper, the assessments of German spent fuel legacy (heavy metal content) and the nuclide composition of this inventory have been done. The methodology used applies advanced nuclear fuel cycle simulation techniques in order to reproduce the operation of the German nuclear power plants from 1969 till 2022. NFCSim code developed by LANL was adopted for this purpose. It was estimated that 10,300 tonnes of unreprocessed nuclear spent fuel will be generated until the shut-down of the ultimate German reactor. This inventory will contain $\sim 131$ tonnes of plutonium, $\sim 21$ tonnes of minor actinides, and 440 tonnes of fission products. Apart from this, ca.215 tonnes of vitrified HLW will be present. As fission products and transuranium elements remain radioactive from $10^{4}$ to $10^{6}$ years, the characteristics of spent fuel legacy over this period are estimated, and their impacts on decay storage and final repository are discussed.
\end{abstract}

\section{Introduction}

As a consequence of the accident in Fukushima, nine power plants (PP) of originally 19 are still connected to the grid in Germany. The PP fleet with total electrical capacity of about 12 GWe consists of light water reactors: 7 pressurised water reactors (PWRs) and 2 boiling water reactors (BWRs). Germany will gradually phase out nuclear power by the end of 2022 at the latest. With the 13th amendment to the Atomic Energy Act (of 6th August 2011) [1] the licence to operate the oldest seven nuclear PPs, Biblis A and B, Brunsbüttel, Neckarwestheim 1, Isar 1, Unterweser, Philipsburg 1 and Krümmel, all closed down during the moratorium in March 2011, has already expired. The operating licences for remaining nuclear PPs will expire between 2015 and 2022 with the latest possible shutdown dates: 2015 for PP Grafenrheinfeld, 2017 for PP Gundremmingen, 2019 for PP Philippsburg, 2021 for PPs Grohnde, Gundremmingen C, and Brokdorf, 2022 for PPs Isar 2, Emsland, and Neckarwestheim 2.
In the past two decades, Germany's objective has changed also in view of spent nuclear fuel (SNF) management. The delivery of spent fuel discharged from power reactors for reprocessing abroad has been prohibited since the mid of 2005, the direct disposal of spent fuel became according to law, the only back-end option. Until 2005 due to the Atomic Energy Act of 1994 which included the requirement of reusing the fissile material contained in SNF, the power plant operators could do both either load plutonium separated during spent fuel reprocessing back to the reactors while fabricating mixed -oxide fuel or store intermediately the spent fuel at the sites of commercial PP for future emplacement in the geological repository. Obviously present day problem of major concern in Germany is a sound and publicly accepted management of generated nuclear waste: SNF and the highlevel waste (HLW) in mid and long time period.

This paper focuses on decay characteristics of German spent fuel legacy and addresses the possible impacts of HLW on management options. First challenge is to determine the 
amount and the concentration of radioactive nuclides in the bulk of spent fuel (heavy metal) inventory which has been produced by German PPs until the fleet closure, that is, till the year 2022. This task was completed with the help of advanced fuel cycle analyses code applied to reproduce the operation performance of each German PP to simulate German phaseout scenario and to track the nuclide concentration in pile versus time, dependant on target burn up and the fresh fuel composition and its evolution out-of-pile over a cooling time storage. All fuel cycle facilities were considered. Hazardous constituents of HLW which might be of most concern for a decay storage safety and can be seen as a part of source term for repository are quantified, and their implications on further management options are discussed.

\section{Assessment of Spent Fuel Amount and Isotopic Composition}

Spent nuclear fuel has been produced in Germany since 1970. Accumulated SNF inventory originates from lightwater reactors loaded with uranium oxide and mixed oxide fuel. When LWR has achieved equilibrium in the production of radioactive species, some 51 new actinides and more than 250 fission products, all radioactive, can be identified in discharged fuel. The extend to which fresh fuel is burned up in the reactor, that is, effective full power days of fuel irradiation in reactor core, determines the inventory of high radioactive waste created. In order to estimate the amount and nuclide composition of aggregated spent fuel, which has been produced by nineteen-unit of the German PP fleet till 2022, simulation studies on German nuclear power phaseout scenario have been performed. Fuel cycle analyses code NFCSim [2] which provides life cycle material balances for diverse, but interconnected reactor fleet facilities was used for this purpose. In NFCSim, both the criticality engine and the burnup engine are embedded. The criticality module operates in transient and equilibrium fuel management regimes at refuelling batch level. To assess the accumulated SNF mass and isotopic content, a dynamic simulation model of German PP fleet was developed. It was validated against published data showing that the main average fleet performance characteristics are reproduced in a consistent manner.

2.1. Simulation Studies of German Phase-Out Scenario. The nuclear phase-out scenario was simulated according to the accelerated power plant retirement schedule [1] approved in 2011. The behaviour of the fleet from the present day through closure of ultimate commercial reactor was estimated based upon extrapolation of current trends. The historical characterization of the German fleet was done using reactor toplevel parameters adopted partly from former study [3]. The entire simulation, from the first delivery of electric power from PP Obrigheim in 1969 through the shutdown of PP Neckar-2 in 2022, was carried out in a single calculation run. Rather than undertaking to recreate each individual cycle for every reactor, reactor key parameters such as load factors, fuel discharge burnups, and cycle lengths were considered such that their fleet-average values represent realistic mean values and well approximate published realities for a given reactor type.

In NFCSim scenario, model 13 PWRs and 6 BWRs were explicitly treated. Eight are PP loaded with U235-enriched uranium oxide (UOX) fuel only; the other eleven are licensed to load both UOX and mixed uranium-plutonium oxide (MOX) fuel. MOX fuel has been used in Germany since 1980. German LWR once through and partially closed fuel cycles including reprocessing (after at least five years cooling) of spent LWR fuel till 2005, and fabrications of MOX fuel were simulated. A set of reactor top-level parameters like thermal power, core inventory, startup and planned shutdown dates, and periods during which MOX capable reactors burn MOX, has been gathered for each facility. Other information, for example, discharge burnup, up and down times for each cycle (load factors), the core fraction of MOX employed by the MOX-capable reactors was not available in full, thus MOX use was estimated on the base of known time intervals during which specific reactors burned MOX [4]. This estimate was guided by published data regarding the amount of German spent fuel that had been reprocessed at facilities in Germany, France, and the UK. Lots of 432 PWR-UOX, 152 PWR-MOX, 231 BWR-UOX, and 31 BWR-MOX fuel batches have been analysed, including transient startup and shutdown ones. For each fuel batch, decay calculations associated with the spent fuel aging, necessary in order to properly estimate the built up and depletion of isotopes, were done with NFCSim code employing ORIGEN burnup and depletion module [5]. Additionally NFCSim is capable to model historical and future changes in fuel burnup and reactor load factors, that is, the collection of the batches generated in the simulation possess age and burnup distribution. This leads to more accurate assessments of nuclide concentration than the commonly used approach to calculate the nuclide inventory in SNF for selected, discrete 2 or 3 representative, and averaged burnup values [6] sufficient however for repository safety studies.

As already mentioned NFCSim simulation spans over the entire time period of PPs operation, that is, from 1969 to 2022 rather than commencing from the present day. This approach was chosen for two main reasons. First, although some published data regarding current German SNF inventories exists, this data is not comprehensive enough with respect to SNF isotopic composition, nor does it adequately discriminate between fuel types. Second, simulating the historical behaviour of the reactor fleet with the aim of reproducing available aggregate SNF inventories affords a good opportunity for benchmarking the reactor fleet parameterization used in NFCSim input model.

The reproduced burnup PP fleet trajectory with average burnup values is shown in Figure 1 inclusive "transient" values, that is, those peculiar to PP startup or shutdown.

2.2. Results. First outcome of NFCSim simulation studies is the estimation of the amount of spent fuel mass produced over time and the cumulative mass of spent fuel reprocessed. To perform the validation of simulation results, three published temporal data points describing the performance of the German nuclear power were compared to the NFCSim 


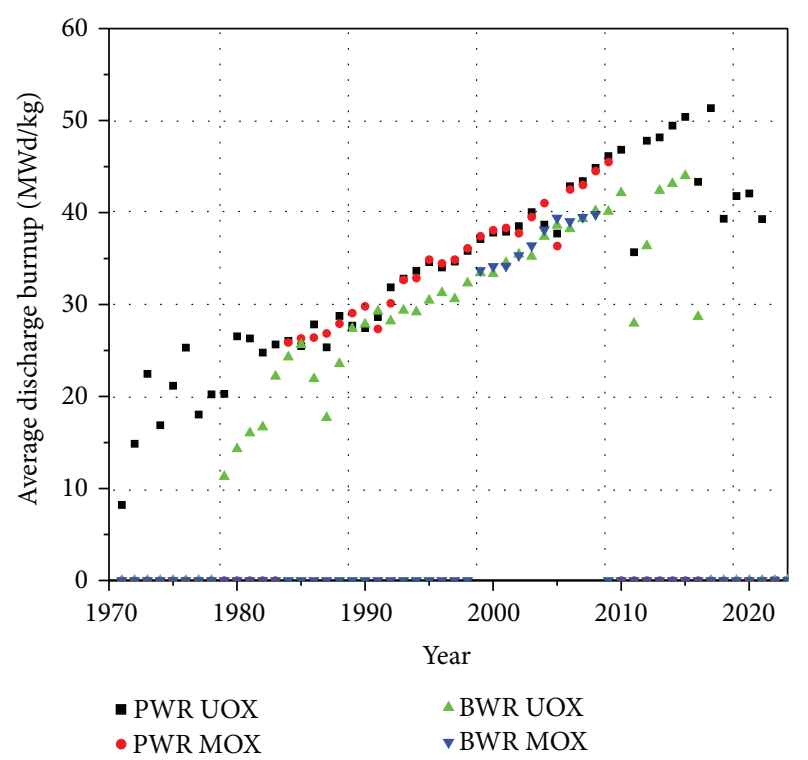

FIGURE 1: Average discharge burnup of annually discharged SNF from German PPs in NFCSim code model.

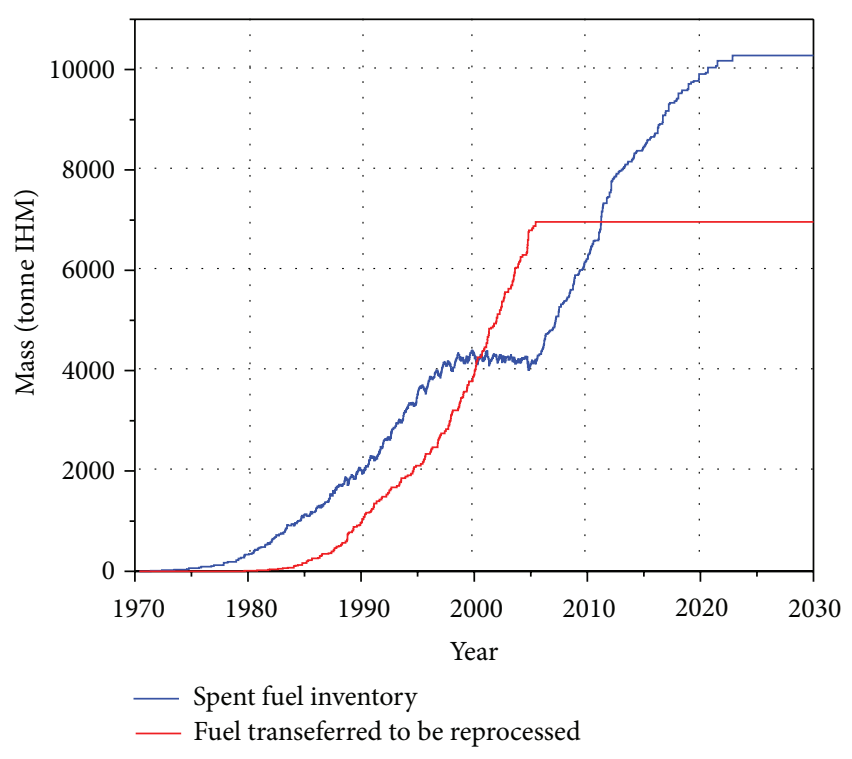

FIGURE 2: Spent fuel inventory and integrated reprocessing throughput for the German reactor fleet.

results. This concerns (1) 8400 tIHM: total mass of SNF discharged from the fleet by 2000 (2) 4000 tIHM: spent UOX fuel mass which had been reprocessed by 2000, and (3) 7000 tIHM: the upper limit of the total amount of reprocessed spent fuel till 2022.

Figure 2 shows the time variation of the aggregate inventory of discharged unreprocessed spent fuel as well as the cumulative amount of UOX fuel transferred for reprocessing during the period 1970-2022.

According to NFCSim predictions, German SNF inventory will in 2022 amount to ca. 10,300 tonnes of initial heavy

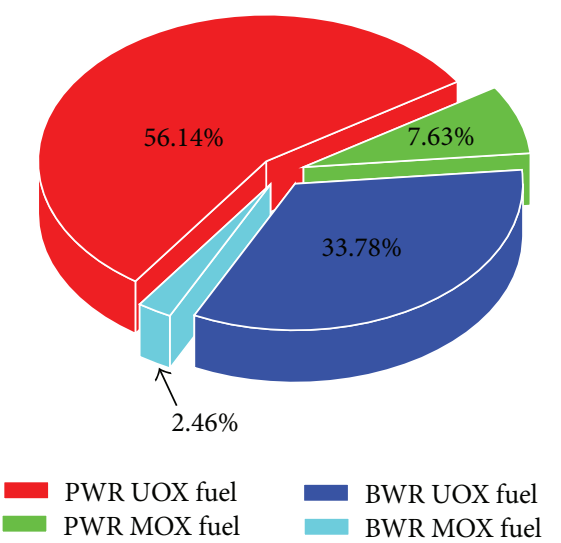

Figure 3: Breakdown by fuel type of accumulated spent fuel mass in 2022 .

metal (IHM). Second important result of NFCSim simulations is the percentage mass breakdown of this inventory with respect to the discharged fuel type shown in Figure 3. Finally, Table 1 contains a mass content of each SNF constituent. The isotopic mass composition of actinides and selected FP in 2022 is detailed in Table 2.

As can be seen in Table 2. the total SNF in 2022 will contain $\sim 131$ tonnes of plutonium and $\sim 21$ tonnes of MA. Note that the compositional data reflects the decay of each fuel batch for the appropriate amount of time following its discharge. Vitrified high-level waste (HLW) is also given in the table. Fission products constitute the bulk-96.4\%-of this waste. The trace actinides present in HLW follow from the assumed $99.8 \%$ recovery efficiency of all transuranics. It should be mentioned that the list of generated FP in Table 2 is not complete and does neither include the concentrations of, for example, Zr-93, Pd-107, Sn-126, Sm-147, and so forth, which might give significant contribution to the total dose in mined repositories (apart from salt medium rock) nor most mobile FPs like Se-79.

Therefore, the physical source term shown in Table 2, especially the radioactivity which is a good indication of potential radiotoxicity might be of limited value for repository safety case investigation as done in [7]. It is, however, relevant for severe accidental situations such as a human intrusion or seismic event leading to the breaches into the repository which are yet not considered in safety assessments for mined repositories.

While analysing Table 2, it can be stated that isotopes: $\mathrm{Cm}-243, \mathrm{Cm}-244$, and Cm-245, are produced in relatively small quantities as compared to Am-241 and Np-237 isotopes. Total mass of accumulated curium amounts to $662 \mathrm{~kg}$ versus 14.6 tonnes of americium and 6.2 tonnes of neptunium, respectively. Half-lives and principal emissions of plutonium isotopes can be found in Table 3. Characteristics of most important minor actinide isotopes are given in Table 4.

Among fission products the most radiotoxic are the longlived isotopes Tc-99, I-129, and Cs-135. Two of them, Tc99 and I-129, are mobile enough in the biosphere to be potential dangers whereas Cs-135 is not highly mobile in the 
TABLE 1: Inventories (tonnes) of the German SNF and HLW in 2022.

\begin{tabular}{lcc}
\hline Constituent & Total SNF & HLW \\
\hline Total & $\mathbf{1 . 0 3 E}+\mathbf{0 4}$ & $2.15 E+02$ \\
$\mathrm{U}$ & $\mathbf{9 . 7 1 E}+\mathbf{0 3}$ & $6.69 E-01$ \\
$\mathrm{Pu}$ & $\mathbf{1 . 3 1 E}+\mathbf{0 2}$ & $1.99 E-01$ \\
$\mathrm{Th}$ & $\mathbf{3 . 2 8 E}-\mathbf{0 5}$ & $7.21 E-06$ \\
$\mathrm{~Pa}$ & $\mathbf{1 . 5 4 E}-\mathbf{0 6}$ & $6.38 E-07$ \\
$\mathrm{~Np}$ & $\mathbf{6 . 2 1 E}+\mathbf{0 0}$ & $2.92 E+00$ \\
$\mathrm{Am}$ & $\mathbf{1 . 4 6 E}+\mathbf{0 1}$ & $3.68 E+00$ \\
$\mathrm{Cm}$ & $\mathbf{6 . 6 2 E}-\mathbf{0 1}$ & $7.06 E-02$ \\
Other MA & $\mathbf{1 . 1 2 E}-\mathbf{0 7}$ & $2.04 E-09$ \\
$\mathrm{Cs}$ & $\mathbf{2 . 9 2 E}+\mathbf{0 1}$ & $1.25 E+01$ \\
$\mathrm{Sr}$ & $\mathbf{8 . 3 0 E}+\mathbf{0 0}$ & $3.49 E+00$ \\
$\mathrm{Tc}$ & $\mathbf{9 . 2 8 E}+\mathbf{0 0}$ & $4.73 E+00$ \\
$\mathrm{I}$ & $\mathbf{2 . 9 7 E}+\mathbf{0 0}$ & $1.49 E+00$ \\
$\mathrm{Ru}$ & $\mathbf{2 . 7 9 E}+\mathbf{0 1}$ & $1.35 E+01$ \\
Lanth & $\mathbf{1 . 1 9 E}+\mathbf{0 2}$ & $5.95 E+01$ \\
Other FP & $\mathbf{2 . 1 9 E}+\mathbf{0 2}$ & $1.12 E+02$ \\
\hline
\end{tabular}

environment. The fission products of the highest concern in the middle term are Sr-90 and Cs-137 [8], mainly because they are the largest radiation emitters, due to their short half-lives and consequently high activity. Principal decay properties of the most hazardous FP nuclides are provided in Table 5.

Above mentioned FP isotopes are present in German spent fuel legacy in considerable quantities. Their inventories in 2022 are of order of several tonnes each: 9.28 tonnes of Tc99, 2.27 tonnes of I-129, 5.43 tonnes of Cs-135, 4.29 tonnes of Sr-90, and 1.04 tonnes of Cs-137, respectively. Cesium 137 is responsible for the majority of external gamma dose at nuclear installations experienced by workers since it decays by beta emission to a metastable nuclear isomer of barium 137 , that is, barium-137 m which has a half-life of about 153 seconds and is responsible for all emissions of gamma rays.

In addition to the individual and aggregated material balances presented above, NFCSim derives a number of quantities related to the disposability of the various waste forms. These are presented in Table 6; both totals and per-ton values are given.

The uncertainties concerned the overall results contained in Tables 1-5 have been examined by cross-checking of ORIGEN calculations versus similar codes like KORIGEN and are addressed in detail in $[3,9]$. Concerning the half-life and branching ratio values for the radio nuclides modelled (halflives greater ten 60 years plus all daughters) in those codes, the uncertainties have been quantified [6] and have been found to have negligible impact on decayed inventories for radio nuclides of relevance for repository safety assessment calculations. With regard to uncertainties associated with cross-section data, a comparison between ORIGEN data set of effective one group cross-sections for neutron-induced reactions and corresponding KORIGEN set can be found in [3].
It is important to underline that the objective of this paper is to reproduce (a) German PP fleet performance simulating industrially implemented fuel cycles over five decades of PPs operation, (b) nuclide inventory present in SNF (c) characteristics of constituent bulk of radio nuclides, and (d) their inventory evolution and impacts. The aim is neither to compare the different fuel cycle options nor to demonstrate the disposal feasibility of NSF in salt, tuff, or deep-borehole [10] type of repository by analysing dedicated safety cases such as the ones considered in [7]. As concerns, a comparison between different fuel cycle options a variant of German phase-out scenario has been extensively studied in [3]. It was postulated there that the reprocessing of UOX fuel in Germany will be extended until 2022. Scenario assessments show in this case a reduced amount of UOX spent fuel subassemblies (SAs) to be disposed off, but significantly higher inventory of MOX SA and vitrified waste to be transferred to repository. If MOX capable PP would continue loading MOX, the aggregate inventory (tons) of discharged unreprocessed SF as of January 1, 2022, would reduce to $50 \%$ for UOX-SA, whereas for MOX-SA it would increase by $75 \%$, and vitrified HLW mass would increase by $80 \%$ as compared with reference case (see [3], Table 2). The SNF plutonium inventory would be reduced by $15 \%$. Additional waste amount of information on NSF inventory and characteristics for different PWR fuel cycle options, open-loading only UOX fuel into PP cores or partly closed with separated plutonium recycling, can be found in $[8,11]$. The impact on decay heat and radiotoxicity evolution of nuclear material mass assessed here can be easily estimated by rescaling to German PP legacy inventory.

As shown, the operation of German PP fleet and SNF are characterized with NFCSim code studies well, although in an approximate sense. The uncertainties caused by burnup, and decay calculation assumptions could be minimized considering in total 845 fuel batches, each of them with proper composition (at BOL and EOL), associated target burn up and age inclusive nuclide depletion due to decay storage time. This level of analyses is an add-on with respect to a commonly applied procedure which is based on discrete, mostly three burnup values [6].

Subsequent sections of this paper address decay characteristics such as the radioactivity, the decay heat, and the radiotoxicity of nuclear material (HM) in realistic, that is, industrially implemented German fuel cycle showing SNF inventories and discuss their evolution in short, middle, and long term. A set of key parameters of concern for the decay storage and relevant to repository accidental intrusion scenarios are delivered. Note that in Table 6 , the radioactivity is expressed both in Curie and Becquerel units, as American codes such as NFCSim use and output non-SI units.

\section{Decay Characteristics of Accumulated Spent Fuel Inventory}

Long-lived radioactive waste such as spent nuclear fuel and vitrified HLW from fuel reprocessing will require long-term management in a final repository. Repository concepts are 
TABLE 2: Selected isotopic inventories (tonnes) in 2022 of German SNF and HLW.

\begin{tabular}{|c|c|c|c|c|c|c|}
\hline Nuclide & PWRUOX & PWRMOX & BWRUOX & BWRMOX & Total SNF & HLW \\
\hline U-233 & $2.14 E-05$ & $1.71 E-06$ & $1.24 E-05$ & $2.73 E-07$ & $3.59 E-05$ & $2.17 E-05$ \\
\hline $\mathrm{U}-234$ & $1.56 E-01$ & $1.43 E-01$ & $1.18 E-01$ & $3.27 E-02$ & $4.50 \mathrm{E}-01$ & $3.79 E-04$ \\
\hline $\mathrm{U}-235$ & $4.84 E+01$ & $1.89 E+00$ & $3.30 E+01$ & $8.10 E-01$ & $8.41 E+01$ & $5.27 E-03$ \\
\hline $\mathrm{U}-236$ & $2.77 E+01$ & $3.72 E-01$ & $1.38 E+01$ & $1.83 E-01$ & $4.21 \mathrm{E}+01$ & $2.42 E-03$ \\
\hline U-237 & $3.13 E-07$ & $7.30 E-08$ & $7.20 E-08$ & $2.11 E-08$ & $4.79 E-07$ & $1.24 E-10$ \\
\hline $\mathrm{U}-238$ & $5.38 E+03$ & $7.12 E+02$ & $3.26 E+03$ & $2.32 E+02$ & $9.58 E+03$ & $6.61 E-01$ \\
\hline $\mathrm{Pu}-238$ & $1.34 E+00$ & $7.40 E-01$ & $7.73 E-01$ & $1.99 E-01$ & $3.05 E+00$ & $2.19 E-03$ \\
\hline $\mathrm{Pu}-239$ & $3.17 E+01$ & $1.64 E+01$ & $1.98 E+01$ & $3.03 E+00$ & $7.10 \mathrm{E}+01$ & $7.68 E-02$ \\
\hline $\mathrm{Pu}-240$ & $1.43 E+01$ & $1.16 E+01$ & $7.62 E+00$ & $3.15 E+00$ & $3.66 \mathrm{E}+01$ & $1.09 E-01$ \\
\hline $\mathrm{Pu}-241$ & $4.64 E+00$ & $2.31 E+00$ & $2.28 E+00$ & $6.67 E-01$ & $9.91 E+00$ & $3.95 E-03$ \\
\hline $\mathrm{Pu}-242$ & $3.72 E+00$ & $3.43 E+00$ & $1.90 E+00$ & $1.07 E+00$ & $1.01 E+01$ & $6.39 E-03$ \\
\hline $\mathrm{Pu}-244$ & $3.05 E-04$ & $4.04 E-04$ & $1.65 E-04$ & $1.18 E-04$ & $9.92 E-04$ & $3.57 E-07$ \\
\hline Th-229 & $1.62 E-09$ & $2.13 E-10$ & $1.28 E-09$ & $1.13 E-11$ & $3.12 E-09$ & $1.42 E-09$ \\
\hline Th-230 & $3.69 E-06$ & $4.95 E-06$ & $3.42 E-06$ & $9.24 E-07$ & $1.30 E-05$ & $9.78 E-07$ \\
\hline Th-232 & $1.18 E-05$ & $2.44 E-07$ & $7.68 E-06$ & $9.81 E-08$ & $1.98 E-05$ & $6.23 E-06$ \\
\hline $\mathrm{Pa}-231$ & $6.68 E-07$ & $6.27 E-08$ & $5.83 E-07$ & $1.92 E-08$ & $1.33 E-06$ & $5.39 E-07$ \\
\hline $\mathrm{Pa}-233$ & $1.31 E-07$ & $8.02 E-09$ & $7.01 E-08$ & $1.71 E-09$ & $2.11 E-07$ & $9.91 E-08$ \\
\hline Np-237 & $3.86 E+00$ & $2.37 E-01$ & $2.07 E+00$ & $5.06 E-02$ & $6.21 E+00$ & $2.92 E+00$ \\
\hline Np-238 & $1.00 E-09$ & $1.75 E-09$ & $1.75 E-09$ & $2.74 E-10$ & $4.77 E-09$ & $1.39 E-09$ \\
\hline Np-239 & $7.87 E-07$ & $5.77 E-07$ & $4.41 E-07$ & $2.11 E-07$ & $2.02 E-06$ & $5.49 E-07$ \\
\hline Am-241 & $3.98 E+00$ & $4.30 E+00$ & $3.01 E+00$ & $9.41 E-01$ & $1.22 \mathrm{E}+01$ & $3.03 E+00$ \\
\hline Am-242 & $6.94 E-08$ & $1.21 E-07$ & $1.21 E-07$ & $1.90 E-08$ & $3.30 E-07$ & $9.59 E-08$ \\
\hline Am-242m & $5.80 E-03$ & $1.01 E-02$ & $1.01 E-02$ & $1.59 E-03$ & $2.77 E-02$ & $8.02 E-03$ \\
\hline Am-243 & $9.14 E-01$ & $6.71 E-01$ & $5.13 E-01$ & $2.46 E-01$ & $2.34 \mathrm{E}+00$ & $6.38 E-01$ \\
\hline $\mathrm{Cm}-242$ & $1.11 E-03$ & $2.48 E-05$ & $2.48 E-05$ & $3.85 E-06$ & $1.16 E-03$ & $1.95 E-05$ \\
\hline $\mathrm{Cm}-243$ & $2.72 E-03$ & $2.32 E-03$ & $1.64 E-03$ & $6.55 E-04$ & $7.34 E-03$ & $1.35 E-03$ \\
\hline $\mathrm{Cm}-244$ & $2.22 E-01$ & $1.76 E-01$ & $1.19 E-01$ & $5.59 E-02$ & $5.72 \mathrm{E}-01$ & $6.05 E-02$ \\
\hline $\mathrm{Cm}-245$ & $1.67 E-02$ & $3.95 E-02$ & $1.15 E-02$ & $6.56 E-03$ & $7.43 E-02$ & $7.93 E-03$ \\
\hline $\mathrm{Cm}-246$ & $2.21 E-03$ & $2.27 E-03$ & $1.38 E-03$ & $8.94 E-04$ & $6.76 E-03$ & $7.85 E-04$ \\
\hline $\mathrm{Cm}-247$ & $2.69 E-05$ & $3.63 E-05$ & $1.93 E-05$ & $1.26 E-05$ & $9.52 E-05$ & $7.82 E-06$ \\
\hline $\mathrm{Cm}-248$ & $1.81 E-06$ & $2.53 E-06$ & $1.46 E-06$ & $7.52 E-07$ & $6.56 E-06$ & $4.22 E-07$ \\
\hline Bk-249 & $5.74 E-10$ & $3.77 E-13$ & $9.50 E-12$ & $6.46 E-14$ & $5.84 E-10$ & $3.71 E-18$ \\
\hline Cf-249 & $2.15 E-08$ & $4.57 E-08$ & $1.99 E-08$ & $1.07 E-08$ & $9.78 E-08$ & $2.02 E-09$ \\
\hline Cf-250 & $2.16 E-09$ & $3.02 E-09$ & $1.51 E-09$ & $8.16 E-10$ & $7.51 E-09$ & $1.34 E-11$ \\
\hline Cf-251 & $2.91 E-10$ & $3.70 E-09$ & $1.08 E-09$ & $8.24 E-10$ & $5.90 E-09$ & $0.00 E+00$ \\
\hline Cf-252 & $1.34 E-11$ & $2.56 E-11$ & $9.94 E-12$ & $6.32 E-12$ & $5.53 E-11$ & $0.00 E+00$ \\
\hline Cs- 134 & $7.81 E-02$ & $3.26 E-04$ & $8.89 E-03$ & $1.60 E-04$ & $8.74 E-02$ & $5.35 E-05$ \\
\hline Cs-135 & $2.92 E+00$ & $6.03 E-01$ & $1.78 E+00$ & $1.26 E-01$ & $5.43 E+00$ & $2.13 E+00$ \\
\hline Cs-137 & $6.54 E+00$ & $6.67 E-01$ & $2.93 E+00$ & $2.37 E-01$ & $1.04 E+01$ & $3.49 E+00$ \\
\hline Sr-90 & $2.86 E+00$ & $1.48 E-01$ & $1.23 E+00$ & $5.47 E-02$ & $4.29 \mathrm{E}+00$ & $1.45 E+00$ \\
\hline Tc-99 & $5.59 E+00$ & $6.92 E-01$ & $2.77 E+00$ & $2.21 E-01$ & $9.28 \mathrm{E}+00$ & $4.73 E+00$ \\
\hline I-129 & $1.32 E+00$ & $2.16 E-01$ & $6.67 E-01$ & $6.63 E-02$ & $2.27 E+00$ & $1.14 E+00$ \\
\hline $\mathrm{Ru}-106$ & $3.15 E-02$ & $5.25 E-06$ & $6.73 E-04$ & $2.36 E-06$ & $3.22 \mathrm{E}-02$ & $1.18 E-08$ \\
\hline
\end{tabular}

TABLE 3: Half-lives and principal radiations of plutonium isotopes.

\begin{tabular}{lccccc}
\hline Isotope & $\mathrm{Pu}-238$ & $\mathrm{Pu}-239$ & $\mathrm{Pu}-240$ & $\mathrm{Pu}-241$ & $\mathrm{Pu}-242$ \\
\hline Half-life $(\mathrm{yr})$ & 87.7 & 24,110 & 6,561 & 14.29 & 374,000 \\
Radiations & $\alpha$ & $\alpha$ & $\alpha$ & $\beta$ & $\alpha$
\end{tabular}

designed by taking into account the waste characteristics such as radionuclide content, decay heat generation, and radiation fields (gamma, neutrons, etc.) [6-8]. Therefore, depletion calculations of the spent fuel (heavy metal) content produced by the German reactor fleet have to be carried out over long time span. NFCSim code version released to KIT delivers some of these characteristics only for the reactor fleet 
TABLE 4: Half-lives and principal radiations of most important $\mathrm{Cm}, \mathrm{Np}$, and Am isotopes.

\begin{tabular}{lcccccc}
\hline Isotope & $\mathrm{Np}-237$ & $\mathrm{Am}-241$ & $\mathrm{Am}-243$ & $\mathrm{Cm}-243$ & $\mathrm{Cm}-244$ & $\mathrm{Cm}-245$ \\
\hline Half-life (yr) & $2,144,000$ & 432.5 & 7,390 & 29.1 & 18.1 & 8,600 \\
Radiations & $\alpha, \gamma$ & $\alpha, n$ & $\alpha, \gamma, n$ & $\alpha, \gamma, n$ & $\alpha, \gamma, n$ & $\alpha$ \\
\hline
\end{tabular}

TABLE 5: Half-lives and principal radiations of the most hazardous fission products.

\begin{tabular}{lcccccc}
\hline Isotope & Tc-99 & I-129 & Cs-134 & Cs-135 & Cs-137 & Sr-90 \\
\hline Half-life $(\mathrm{yr})$ & 211,110 & $15,700,000$ & 2.06 & $2,300,000$ & 30.08 & 28.9 \\
Radiations & $\beta$ & $\beta$ & $\beta$ & $\beta$ & $\beta, \gamma$ & $\beta$ \\
\hline
\end{tabular}

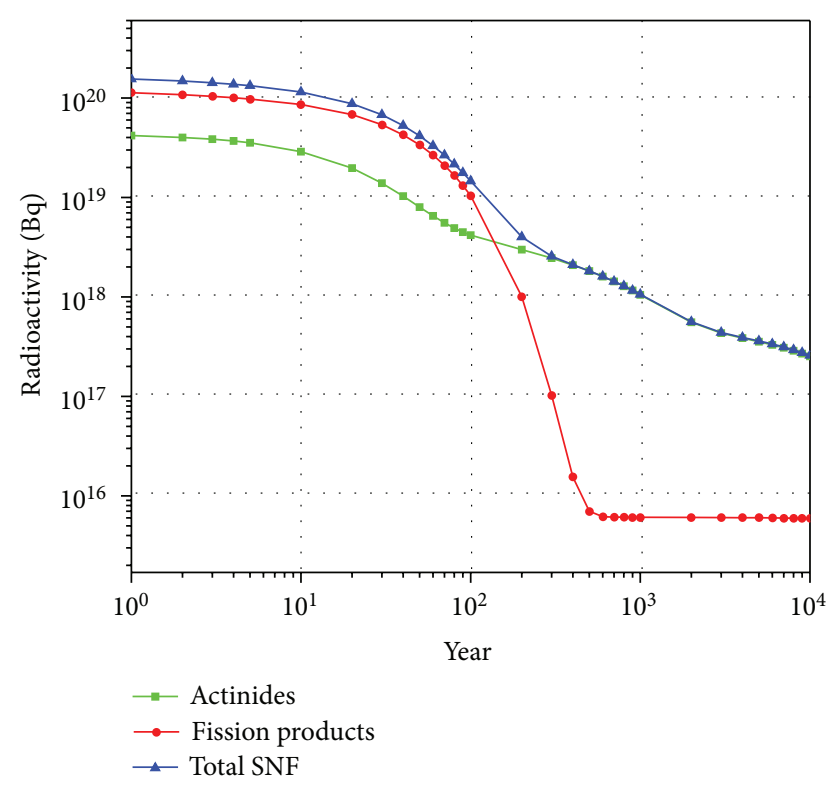

FIGURE 4: Radioactivity evolution of German spent nuclear fuel.

operation period extended by one decade of SNF cooling after the ultimate reactor shutdown. Thus in order to calculate buildup and depletion of nuclides contained in the spent fuel legacy in the longer term, covering 37 decay periods from 1 to 10,000 years, KORIGEN code [12] was used. The nuclide content in SNF inventory input to KORIGEN corresponds to NFCSim predictions as for the January, 1st, 2023, (given in Table 3).

3.1. Radioactivity. Variation of radioactivity with decay time for the stored SNF inventory is depicted in Figure 4. Note that the beginning of the time scale corresponds to the year 2023.

The total radioactivity is dominated for the first 100 years by fission products (with a share of $80 \%$ ). In the intermediate period from 100 till 300 years both fission products and actinides contribute significantly to the total. Finally, in the long term (after 300 years), the long-lived actinides determine the radioactivity.

Additional calculations performed with KORIGEN code indicate that during the first year the following will occur:

(1) Relatively few fission products, namely, cesium, ruthenium, rhodium, barium, yttrium, and strontium will supply ca. $73 \%$ of the total radioactivity due to four separate decay chains displayed in Figure 5.

(2) For all the remaining radioactivity, that is, $27 \%$ only one additional fission product Cs-134 and three actinides: $\mathrm{Pu}-241, \mathrm{Am}-241$, and $\mathrm{Cm}-244$ are responsible.

After 100 years, radioactivity decreases by a factor of 10 with the fission products Sr-90, Y-90, Cs-137, and Ba$137 \mathrm{~m}$ contributing to $70 \%$ of the total. Later, the radioactivity diminishes by a factor of 40 (after 200 years) and reduces further on by a factor of 60 after 300 years (at 2322). In the time period from 2122 till 2322, the contribution from actinides starts to grow up from ca. $30 \%$ at the beginning to $75 \%$ in the year 2222 and finally to $96 \%$ at 2322 . Actinides with significant contribution include Am-241, plutonium (especially $\mathrm{Pu}-239, \mathrm{Pu}-240$, and $\mathrm{Pu}-238$ ) and to smaller extend curium isotopes and $\mathrm{Np}-239$.

Long-lived actinides determine the activity from 400 years (share $>99 \%$ ) till 10,000 years (share 97\%). The predominate nuclides include $\mathrm{Pu}-239, \mathrm{Pu}-240$, and $\mathrm{Am} 241$ in the mid term and $\mathrm{Np}-239, \mathrm{Pu}-239, \mathrm{Pu}-240$, and $\mathrm{Am}-$ 243 in the long term. Around 10,000 years of storage, the activity reduces by a factor of 600 with respect to the initial value. As concerns, extremely long extended storage, greater than 100,000 years (not shown in Figure 4), only one major fission product $\mathrm{Tc}-99$, one actinide $\mathrm{Pu}-239$, and uranium decay daughters generate the largest contribution to the radioactivity.

3.2. Heat Generation. The decay heat from the nuclear waste stream has an impact on the design of storage casks placed in interim storages, shipping, repository footprint, and utilisation. The decay heat of spent fuel which was out of pile in subsequent years of German fleet operation was calculated with the NFCSim code. At any given time, the heat evaluation is carried out in NFCSim based upon all materials that have been out of pile for longer than five years. Younger SNF is discounted because the presence of very short-lived nuclides would render the results difficult to interpret. Figure 6 shows the decay heat load versus time evaluated until 2032 which was generated by aggregate spent fuel (not reprocessed) unloaded from reactors in the time period 1970-2022. It can be noticed that heat generation grows sharply from 2005 on with a rate driven by heat emissions from decay processes of radio nuclides contained in the spent fuel. 
TABLE 6: Properties of the German SNF and HLW (evaluated in 2022 unless otherwise noted).

\begin{tabular}{|c|c|c|c|c|c|c|}
\hline Quantity & $\begin{array}{c}\text { PWR-UOX } \\
\text { (total/per ton) }\end{array}$ & $\begin{array}{l}\text { PWR-MOX } \\
\text { (total/per ton) }\end{array}$ & $\begin{array}{c}\text { BWR-UOX } \\
\text { (total/per ton) }\end{array}$ & $\begin{array}{c}\text { BWR-MOX } \\
\text { (total/per ton) }\end{array}$ & $\begin{array}{c}\text { All SNF } \\
\text { (total/per ton) }\end{array}$ & $\begin{array}{c}\text { HLW } \\
\text { (total/per ton) }\end{array}$ \\
\hline Alpha activity $(\mathrm{Bq})$ & $1.9092 E+18$ & $1.6872 E+17$ & $1.4356 E+18$ & $4.514 E+17$ & $5.4797 E+18$ & $5.772 E+17$ \\
\hline$(\mathrm{MCi})$ & 51.6 & 45.6 & 38.8 & 12.2 & 148.1 & 15.6 \\
\hline Spec. activity (MCi/ton) & $8.94 E-03$ & $5.81 E-02$ & $1.12 E-02$ & $4.83 E-02$ & $1.44 E-02$ & $7.2 E-02$ \\
\hline \multirow{2}{*}{$\begin{array}{l}\text { Gamma decay power } \\
\text { (MW) }\end{array}$} & 2.30 & 0.23 & 1.16 & 0.08 & 3.78 & 1.20 \\
\hline & $3.99 E-04$ & $2.96 E-04$ & $3.34 E-04$ & $3.29 E-04$ & $3.68 E-04$ & $5.61 E-03$ \\
\hline \multirow{2}{*}{$\begin{array}{l}\text { Spont. fission neutrons }\left(\times 10^{9}\right. \\
\mathrm{n} / \mathrm{s})\end{array}$} & 2090 & 1994 & 1346 & 636 & 6066 & 682 \\
\hline & $3.62 E-01$ & $2.54 E+00$ & $3.88 E-01$ & $2.52 E+00$ & $5.90 E-01$ & $3.18 E+00$ \\
\hline \multirow{2}{*}{ Decay power in $2026^{\mathrm{a}}(\mathrm{MW})$} & 7.23 & 1.89 & 3.46 & 0.54 & 13.12 & 3.09 \\
\hline & $1.22 E-03$ & $2.41 E-03$ & $1.0 E-03$ & $2.14 E-03$ & $1.28 E-03$ & $1.44 E-02$ \\
\hline \multirow{2}{*}{ Decay power in $2122(\mathrm{MW})$} & 1.89 & 1.01 & 1.05 & 0.26 & 4.21 & 0.57 \\
\hline & $3.28 E-04$ & $1.29 E-03$ & $3.02 E-04$ & $1.02 E-03$ & $4.09 E-04$ & $2.68 E-03$ \\
\hline \multirow{2}{*}{$\begin{array}{l}\text { Decay heat integral } \\
(\mathrm{MW}-\mathrm{yr})\end{array}$} & 913 & 649 & 539 & 161 & 2262 & 206 \\
\hline & $1.58 E-01$ & $8.28 E-01$ & $1.55 E-01$ & $6.37 E-01$ & $2.20 E-01$ & $9.60 E-01$ \\
\hline \multirow{2}{*}{ Inh. Radiotoxicity $^{\mathrm{c}}(\mathrm{Sv})$} & & & & & $1.15 E+13$ & \\
\hline & & & & & $1.12 E+06$ & \\
\hline \multirow{2}{*}{ Ing. Radiotoxicity ${ }^{\mathrm{c}}$ (Sv) } & & & & & $6.05 E+10$ & \\
\hline & & & & & $5.89 E+03$ & \\
\hline
\end{tabular}

${ }^{a}$ Evaluated at 2026 in order to allow short-lived nuclides from recently discharged batches to decay.

${ }^{\mathrm{b}}$ Integral of decay power over 1900 year period commencing in 2123.

${ }^{c}$ Long-term radiotoxicities evaluated from concentrations following 10,000 year decay.

$$
\begin{aligned}
& \text { Sr-9028.79 y } \longrightarrow \mathrm{Y}-90_{64} \mathrm{~h} \longrightarrow \mathrm{Zr}-90_{\text {stable }} \\
& \text { Ru-106 } 373.59 \mathrm{~d} \longrightarrow \text { Rh-106 } 29.8 \mathrm{~s} \longrightarrow \text { Pd-106 } \\
& \text { Cs-13730.07 y } \longrightarrow \text { Ba- } 137 \mathrm{~m}_{2.552 \mathrm{~m} \longrightarrow \text { Ba-137 }} \longrightarrow \text { stable } \\
& \text { Ce-144284.893 d } \longrightarrow \text { Pr-14417.28 m } \longrightarrow \text { Nd-1442.29E+15 y } \longrightarrow \text { Ce-140 stable }
\end{aligned}
$$

FIGURE 5: Decay series with major contribution to FP radioactivity during the first year after fuel unload.

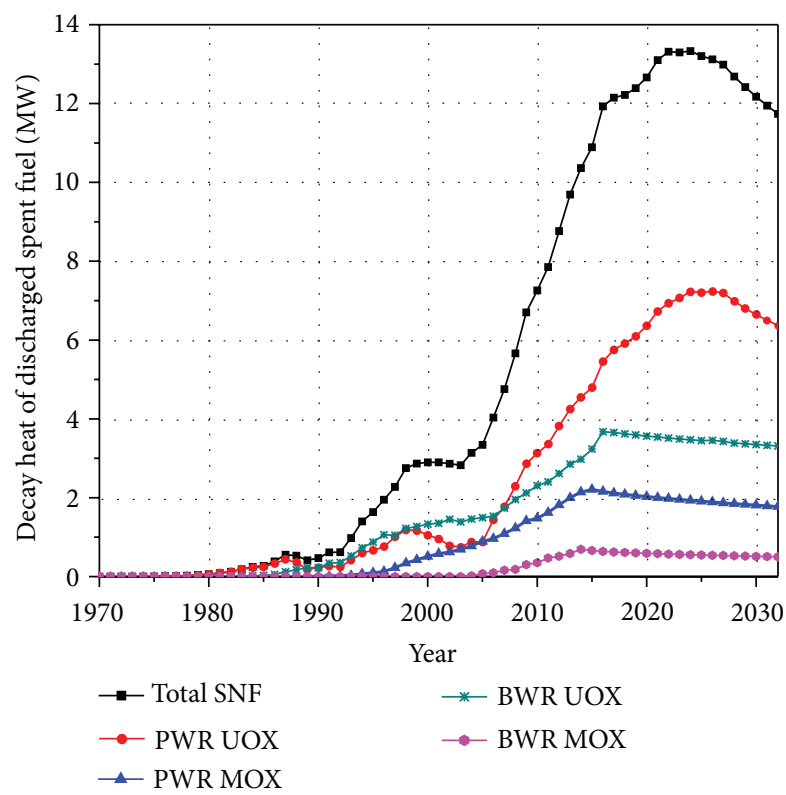

FIGURE 6: Decay power of accumulated spent nuclear fuel at date shown.
To further quantify the implications on disposal options, the decay power of all nuclear material present in the system was evaluated in NFCSim studies at several points in time. The decay power of stored SNF inventory following 100 years of cooling is shown in Figure 7. Note that in this figure, the value given at each year reflects the heat production of all material that is out of pile in this year but evaluated 100 years later. This figure is relevant to long-term interim storage needs or to the early phases of repository operation, depending on the disposal strategy pursued. The long-term decay heat, that is, the decay power integrated over a period extending from 100 to 2000 years in the future is displayed in Figure 8. This key parameter is relevant for repository operation, that is, design of gallery lengths and cooling system design after emplacement of HLW and closure of repository.

Additionally, the total heat generated by SNF mass out of pile in 2022 decaying in the storage which can be (according to a time scale) a pool, an interim storage facility or final repository was assessed up to 10,000 years using the KORIGEN code. The decay heat variation with the storage time is displayed in Figure 9. 


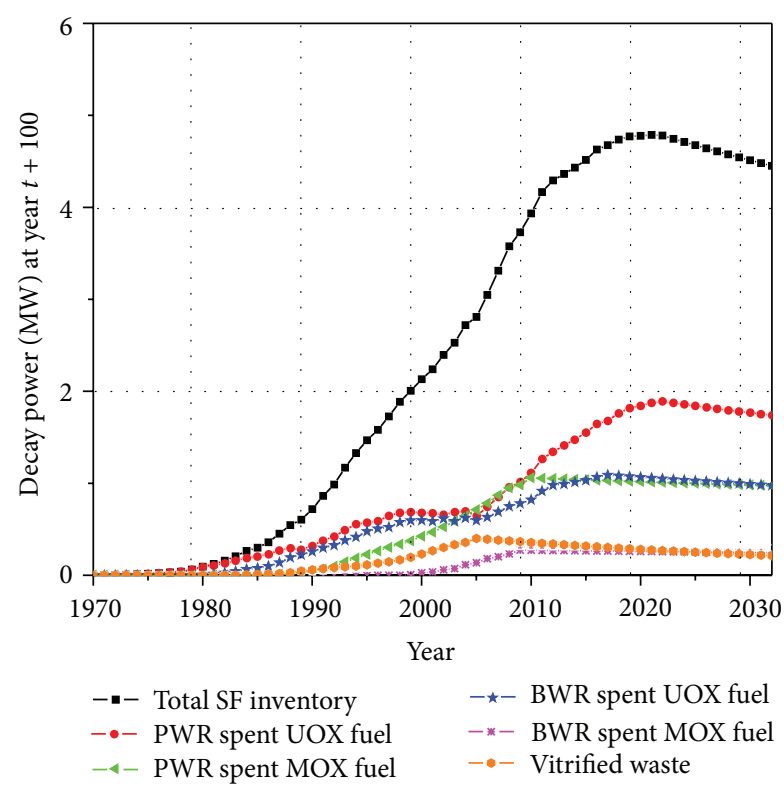

FIGURE 7: Decay power of stored nuclear material (SNF and vitrified HLW) hundred years after date is shown.

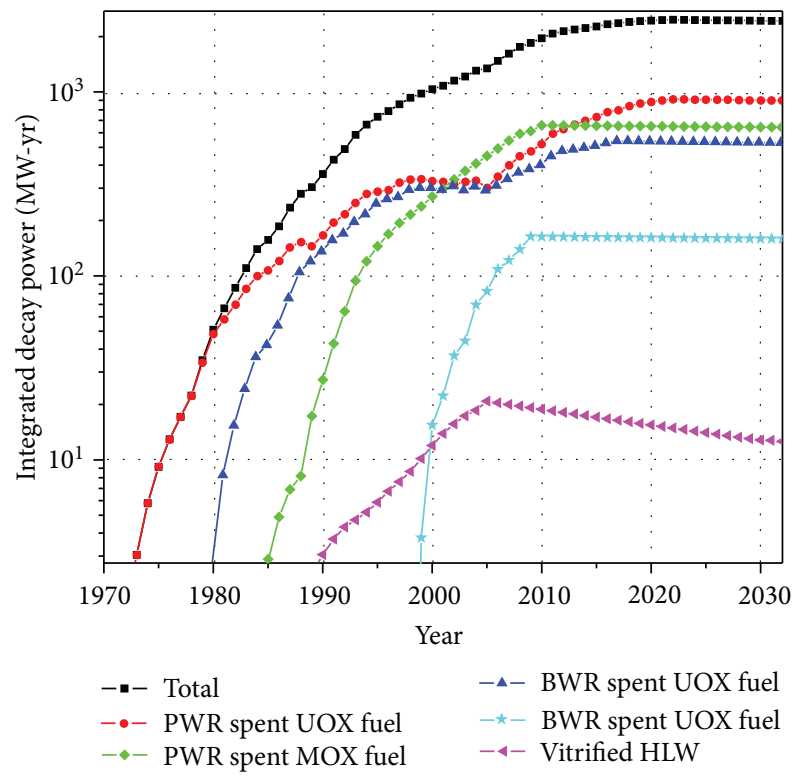

FIGURE 8: Decay power of stored nuclear material (SNF and vitrified HLW) integrated over the period from 100 to 2000 years after data shown.

As was the case for the total radioactivity (discussed in Section 3.1), decay heat production is initially, at storage $<30$ years, determined by fission products. After longer cooling time, the contribution of FP decreases, and decay heat power is determined by actinides. Apparently, the actinides deliver the equivalent output after nearly three decades of decay storage. The initial heat load (1 year) of ultimately discharged, that is, chronologically youngest SNF batches placed in a storage facility originates from three fission products $\mathrm{Rh}-106$, Cs-134, and Pr-144, all of which have short half-lives. At

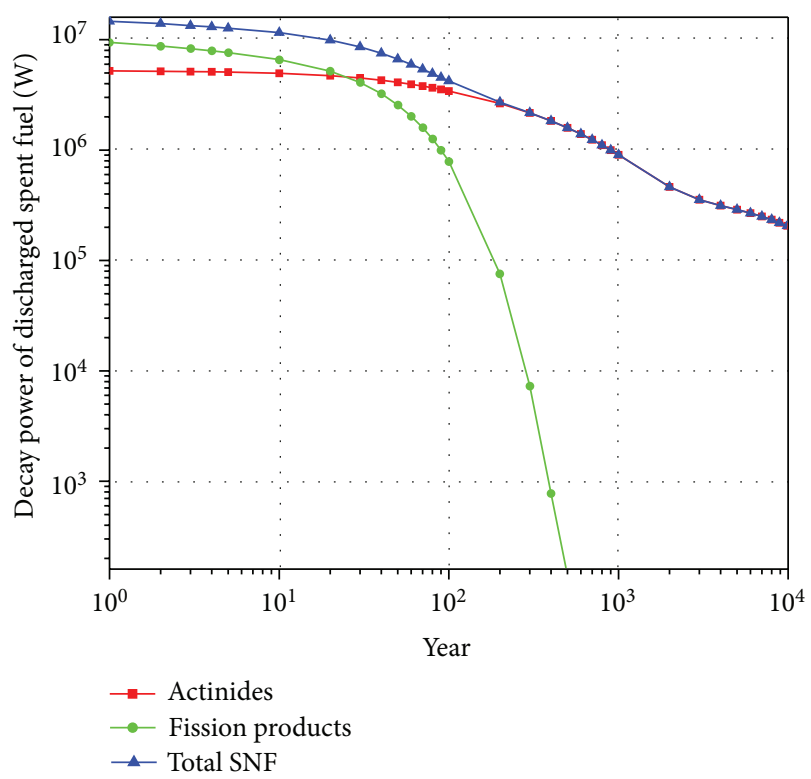

FIGURE 9: Decay heat generated by accumulated spent fuel mass out of pile in 2022 with fission product and actinides components.

storage time of nearly 100 years, the contribution of fission products to the total power amounts to $19 \%$, mainly due to $\mathrm{Sr}, \mathrm{Y}, \mathrm{Ba}$, and $\mathrm{Cs}$ heat production. This share becomes smaller than $1 \%$ after 300 years. The released total thermal power decreases by nearly three orders of magnitude (factor of 720) at 10,000 years.

Figure 10 shows that nuclides which control the heat load in the long-term storage (300 to 1000 years) are $\mathrm{Pu}-238$, $\mathrm{Pu}-239$, and $\mathrm{Am}-241$. In the very long time frame $(10,000$ years), the significant contribution stems from $\mathrm{Pu}-239, \mathrm{Pu}-$ 240, Am-243, Pu-242, and neptunium (Np-237 and Np-239). At 100,000 years (not included in Figure 10), Pu-239 is the major heat-generating isotope.

3.3. Radiotoxicity. The concept of radiotoxicity was introduced in order to compare the radiological hazard of different nuclides. Radiotoxicity $R$, expressed in Sieverts ([Sv]), represents a hypothetical dose and is calculated for a specific nuclide by multiplying its activity $A$ with its dose coefficient $F([\mathrm{~Sv} / \mathrm{Bq}])$ :

$$
R=F \cdot A
$$

For a particular nuclide, two types of radiotoxicity can be distinguished in dependence on whether it is inhaled or ingested by a human (small children being more sensitive to radiation than adults). Due to large variations in the biological effects of different radiation, different types of radiation yield quite different radiotoxicities.

The dose coefficients are evaluated by the International Commission on Radiological Protection, ICRP, and issued periodically in order to update the radiotoxicity calculations. Table 7 taken from Ref. [13] contains dose coefficients for ingestion and inhalation for some important nuclides in spent fuel as recommended by ICRP in 1996. 
TABLE 7: Dose coefficients (adult humans) for intake by ingestion and inhalation for important nuclides present in the German spent fuel legacy.

\begin{tabular}{|c|c|c|c|c|c|}
\hline \multicolumn{3}{|c|}{ Transuranic elements } & \multicolumn{3}{|c|}{ Fission products } \\
\hline \multirow{2}{*}{ Nuclide } & \multicolumn{2}{|c|}{ Dose coefficient (nSv/Bq) } & \multirow{2}{*}{ Nuclide } & \multicolumn{2}{|c|}{ Dose coefficients (nSv/Bq) } \\
\hline & Ingestion & Inhalation & & Ingestion & Inhalation \\
\hline Np-237 & 110 & 23000 & Se-79 & 2.9 & 2.6 \\
\hline $\mathrm{Pu}-238$ & 230 & 46000 & Sr-90 & 28 & 36 \\
\hline $\mathrm{Pu}-239$ & 250 & 50000 & Zr-93 & 1.1 & 10 \\
\hline $\mathrm{Pu}-240$ & 250 & 50000 & Tc-99 & 0.64 & 4 \\
\hline $\mathrm{Pu}-241$ & 4.8 & 900 & Pd-107 & 0.037 & 0.085 \\
\hline $\mathrm{Pu}-242$ & 240 & 48000 & Sn-126 & 4.7 & 28 \\
\hline Am-241 & 200 & 42000 & I-129 & 110 & 15 \\
\hline Am-242m & 190 & 37000 & Cs-135 & 2 & 3.1 \\
\hline Am-243 & 200 & 41000 & Cs-137 & 13 & 9.7 \\
\hline $\mathrm{Cm}-242$ & 12 & 5200 & & & \\
\hline $\mathrm{Cm}-243$ & 150 & 31000 & & & \\
\hline $\mathrm{Cm}-244$ & 120 & 27000 & & & \\
\hline $\mathrm{Cm}-245$ & 210 & 42000 & & & \\
\hline
\end{tabular}

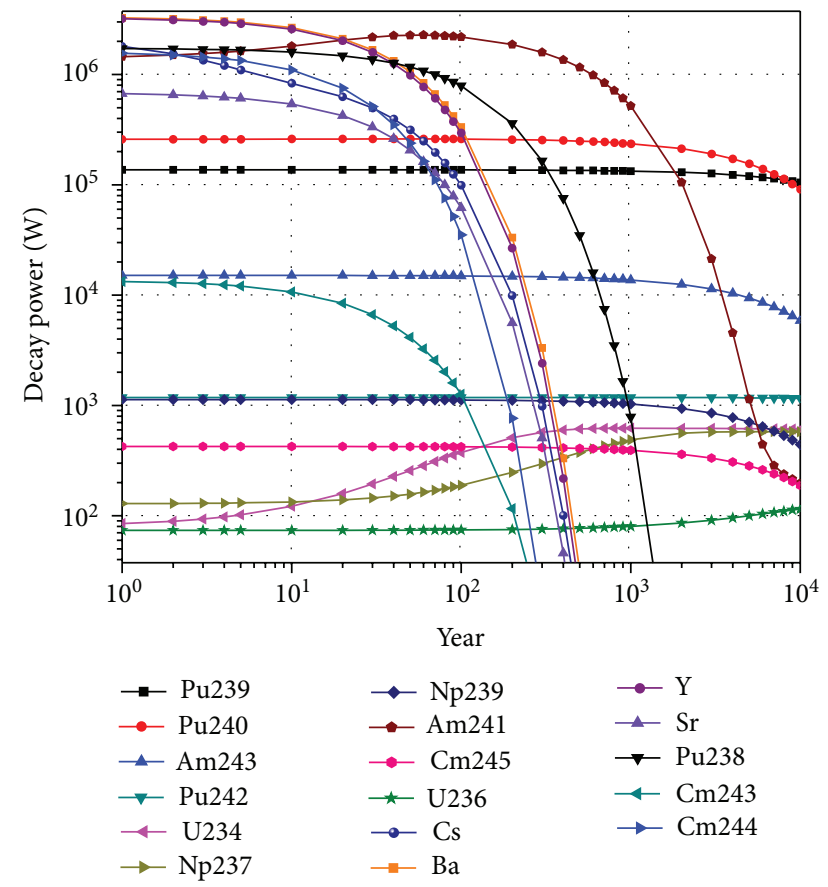

FIGURE 10: Major contributors to decay power generated by stored SNF in the time period from 1 to 10,000 years.

Doses for ingestion and inhalation present in Table 7 show large differences. In particular for actinides, the inhalation possesses a much greater hazard than the ingestion does. It can be noticed that the dose coefficients for the transuranic nuclides are significantly higher than that for most of the important fission products with exception of $\mathrm{Pu}-241$ and $\mathrm{Cm}$ 242 which both cause relatively low damage in humans when ingested. Among fission products, I-129 has a considerable threat due to its peculiar biological properties, that is, the concentration in the thyroid gland where it remains for a long time after intake.

The radiotoxicity of ingestion and inhalation for the German spent fuel was assessed with KORIGEN code. It represents a sum of contributions derived by individual radioactive nuclides contained in SNF legacy versus time. The evolution of the total ingestion radiotoxicity split-up into contributions from actinides and fission products is displayed in Figure 11. As clearly visible in Figure 11, during the first decade of storage, the contribution of fission product to ingestion radiotoxicity remains more or less at the same level as that emanating from the actinides. After 300 years when Cs-137 and Sr-90 decay, the contribution originating from fission products drops rapidly by five orders of magnitude and stabilizes at almost constant level from 1000 till 10,000 years. The contribution from actinides remains significant for much longer time and decreases with slower rate. Plutonium isotopes are dominating initially and in the long time perspective. At 10,000 years, contributions from $\mathrm{Pu}-239, \mathrm{Pu}-$ 240, $\mathrm{Pu}-242, \mathrm{Am}-243, \mathrm{~Np}-237$, and Cm-245 determine the total. Finally, after one million years of storage, the total ingestion radiotoxicity reduces by three orders of magnitude with respect to its initial amount.

The inhalation radiotoxicity is reported in Figure 12. As expected, in the whole decay period considered, the total value is determined by actinides only. The radiotoxicity of vitrified HLW is not included in the Figures 11 and 12 because MA and FP have been immobilised in the borosilicate glass matrix reducing the intake probability significantly.

\section{Conclusions}

The German scenario for phasing-out nuclear energy was fully analysed applying new accelerated reactors shutdown 


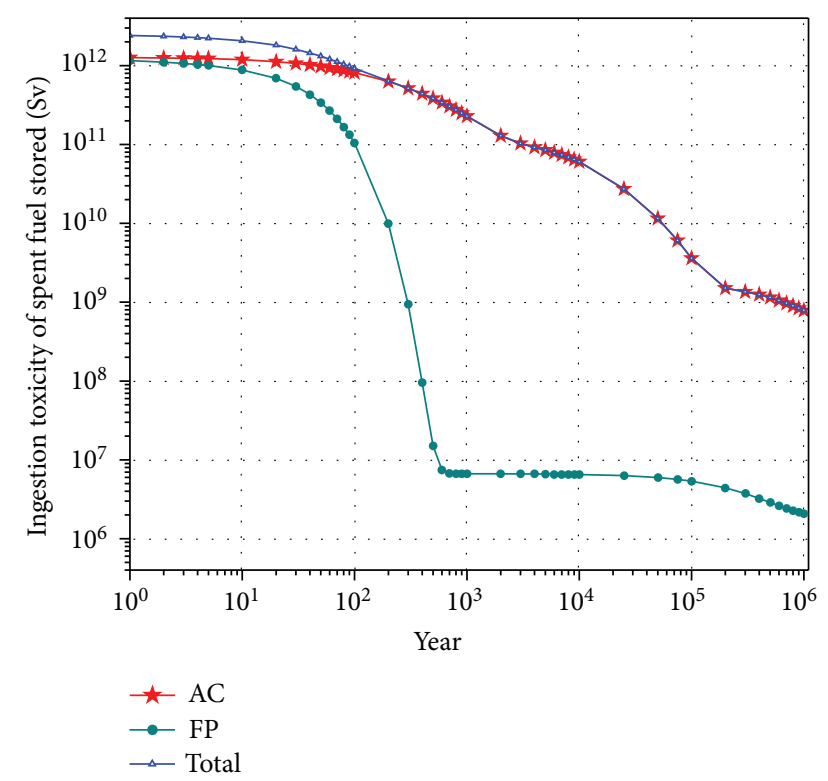

FIGURE 11: Ingestion radiotoxicity of stored SNF with contributions of actinides and fission products.

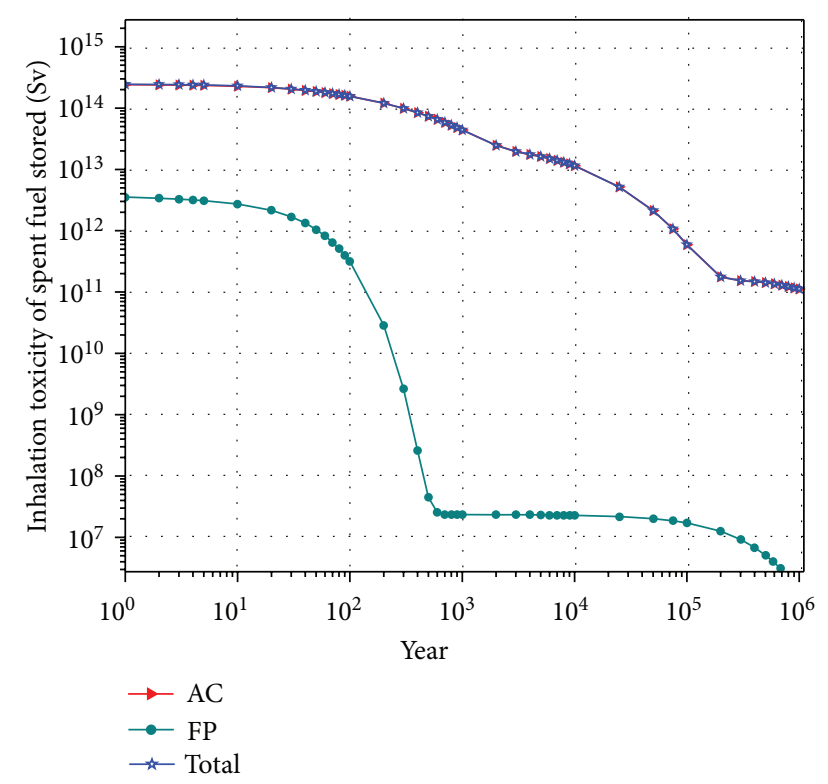

FIGURE 12: Inhalation radiotoxicity of stored SNF with contributions of actinides and fission products.

schedule as specified in the 13th amendment to the Atomic Energy Act of 6th August 2011. Nuclear fuel cycle simulation code NFCSim was used for this purpose. The simulation model was developed to be able to reproduce the performance of each reactor in the German nineteen-PP fleet commencing with first criticality of the oldest PWR "Obrigheim" in 1969 and finishing with the shutdown of the final power plant PWR "Neckar-2" in 2022. Lots of 845 singular fuel batches were analysed with clear distinction between PWR-UOX, PWR-MOX, BWR-UOX, and BWR-MOX fuel type, taking into account PP-specific fresh fuel enrichment (U-235 or Pufissile, resp.), the effective full power days (target burnup), and the aging of spent fuel SA in decay storage.

The primary objective of fuel cycle simulations was to calculate nuclides evolution in a fuel cycle: "in pile", that is, under fuel irradiation conditions and "out of pile", that is, during fuel decay or transport period outside the reactors in order to estimate an amount and the isotopic composition of the German spent fuel legacy. Results show that the overall spent fuel inventory discharged from the German nineteen LWRs until 2022 will amount to nearly 10,300 tonnes IHM (taking into account the residual electricity amount assigned by law to each PP in operation, rather than latest shutdown date which seems to be purely hypothetical). The composition of NSF inventory was calculated at a batch level of resolution, that is, for each type of fuel and reactor operating conditions, including reactor startup and shutdown batches. It was confirmed that the spent uranium oxide fuel dominates legacy content with a share in mass of ca. $90 \%$ (about $56 \%$ from PWRs and $34 \%$ from BWRs). Spent mixed oxide fuel contributes by $10 \%$ (7.6\% from PWRs and $2.4 \%$ from BWRs) as it is a case in France for N4 PPs loading PWR-UOX and MOX. A detailed isotopic breakdown exhibit, as expected, high uranium nuclides share over $94 \%$ of the total SNF mass content. Mass fractions of other substantial actinides are in 2022: $1.27 \%$ of $\mathrm{Pu}, 0.14 \%$ of $\mathrm{Am}, 0.06 \%$ of $\mathrm{Np}$, and $0.006 \%$ of $\mathrm{Cm}$. Minor actinides such as neptunium, americium, and curium are formed by neutron capture during fuel irradiation in the core. The amount of these products is small when the fuel burnup is low, particularly the amount of curium, but the yield becomes more significant when the burnup increases or when plutonium is loaded into the core as it is the case of MOX fuel burning PP. The second important group of nuclides contained in the SNF are fission products. The concentrations (by the year 2022) of the most significant short-and long-lived FP impacting the decay characteristics are $0.04 \%$ of Sr-90, $0.10 \%$ of Cs-137, $0.05 \%$ of Cs- $135,0.02 \%$ of I-129, and $0.02 \%$ of Tc-99. Other species such as, Zr-93, Pd-107, Sn-126, and Sm-147 which might give significant contribution to the total dose in mined repositories (apart from salt medium rock), and most mobile FPs like Se-79 were not traced. Safety case assessment of conventional repository in salt, tuff, or crystalline rock media was here considered out of scope since it requires separate extensive investigation and demonstration of disposal feasibility done by authorized institutions like GRS in Germany, NAGRA in Switzerland, ANDRA in France, and so forth.

On the basis of calculated nuclide inventories, decay characteristics of spent fuel mass cooled in wet or dry storage facilities were derived. Time-dependent behaviour of radioactivity, decay thermal power, and radiotoxicity were evaluated over a 10,000-year period. For both ingestion and inhalation radiotoxicity, the monitoring was extended up to $1,000,000$ years, since such a long period can be relevant for human intrusion scenario into a geological repository. Calculation results quantify the activity, decay heat and radiotoxicity initial level, and their reduction rates over time and indicate that after 200 years the major contributions stem from actinides and their progenies, the decay characteristic 
of which (half-lives, decay mode, and specific heat release) determine the shape of corresponding evolution curves. Especially plutonium, MA, and some fission products, I129, Cs-135, Tc-99, are of particular concern for long-term storage and management, because their half-lives are very long and most of the hazard stems from them when released into the environment. Therefore, their disposal requires immobilisation in glass matrix and the isolation in the stable deep geological formation. Results obtained here deliver a source term for deep-borehole repository [13] or a part of source term for mined repositories relevant for intrusion accidental scenarios or seismic event leading to the breaches into the repository which are yet not considered in safety assessments for conventional repositories thus providing first overall insight on design needs for different types of repositories in various host medium formations [14].

\section{Acknowledgments}

NFCSim code developed at LANL was used as software tool to simulate the fuel cycles. A collaboration with Professor E. A. Schneider from the University of Texas at Austin, USA, and his support in scenario studies carried on in 2004 [3] are highly appreciated.

\section{References}

[1] Dreizehntes Gesetz zur Änderung des Atomgesetzes (13. AtGÄndG), v. 31. 07. 2011 BGBl. I S., 1704 (Nr. 43).

[2] E. A. Schneider, C. G. Bathke, and M. R. James, "NFCSIM: a dynamic fuel burnup and fuel cycle simulation tool," Nuclear Technology, vol. 151, no. 1, pp. 35-50, 2005.

[3] E. Schneider, M. Salvatores, J. Knebel, W. Maschek, A. Schwenk-Ferrero, and H. W. Wiese, "NFCSim scenario studies of German and European reactor fleets," LA-UR-04-4911, http://www.iket.fzk.de/cube/lib/files/ cf87f8b74d3a0e02bb5a7e520b62a9a0.pdf.

[4] D. Porsch, W. Stach, P. Charmensat et al., Plutonium Recycling in LWRs at Framatome ANP-Status and Trends, ANFM, Hilton Head Island, SC, USA, 2003.

[5] A. G. Croff, "ORIGEN2: a versatile computer code for calculating the nuclide composition and characteristics of nuclear materials," Nuclear Technology, vol. 62, pp. 335-352, 1983.

[6] D. F. McGinnes, "Model radioactive waste inventory for reprocessing waste and spent fuel," NAGRA Technical Report 01-01, 2002.

[7] “Project opalinus clay, safety report," NAGRA Technical Report 02-05, 2002.

[8] OECD-NEA Report, "Advanced nuclear fuel cycles and radioactive waste management," NEA No. 5990, OECD, 2006.

[9] A. Schwenk-Ferrero, A. Rineiski, H. W. Wiese, and W. Maschek, "Validation of KORIGEN heat assessment for EFIT-cores," in Proceedings of the Annual Meeting on Nuclear Technology (JK 2007), Karlsruhe, Germany, May 2007.

[10] P. V. Brady, B. W. Arnold, G. A. Freeze et al., "Deep borehole disposal of high-level radioactive waste," http://prod .sandia.gov/techlib/access-control.cgi/2009/094401.pdf.

[11] ftp://ftp.cordis.europa.eu/pub/fp6-euratom/docs/red-impactfinal-published-report_en.pdf.
[12] U. Fischer and H. W. Wiese, "Verbesserte konsistente Berechnung des nuklearen Inventars abgebrannter DWR-Brennstoffe auf der Basis von Zell-Abbrand Verfahren mit KORIGEN," Report KfK 3014, Forschungszentrum Karlsruhe, 1983.

[13] D. Westlén, "Reducing radiotoxicity in the long run," Progress in Nuclear Energy, vol. 49, no. 8, pp. 597-605, 2007.

[14] M. Salvatores, H. Geckeis, K. Gompper et al., "NSC-WPFC task force on potential benefits and impacts of advanced fuel cycles with actinide partitioning and transmutation (WPFC/TFPT)," in Proceedings of the International Conference on GLOBAL 2011, Makuhari, Japan, 2011. 


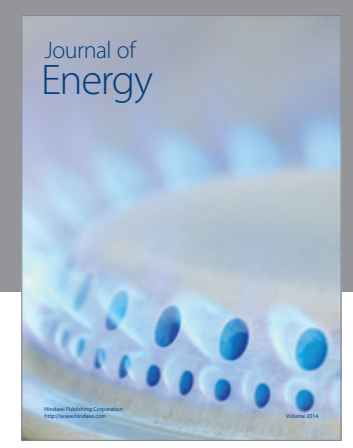

Journal of

Industrial Engineering
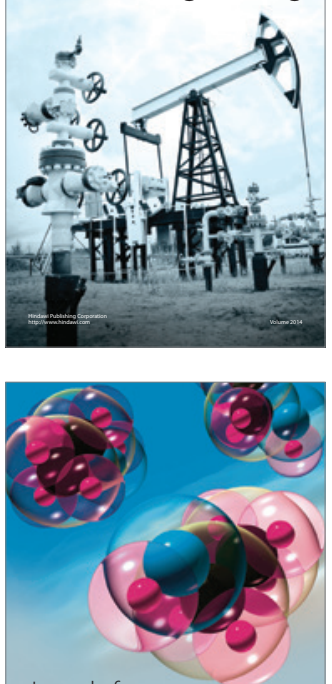

Fuels
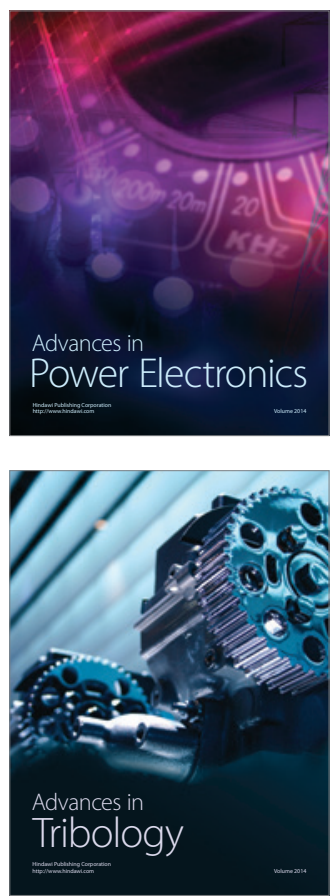

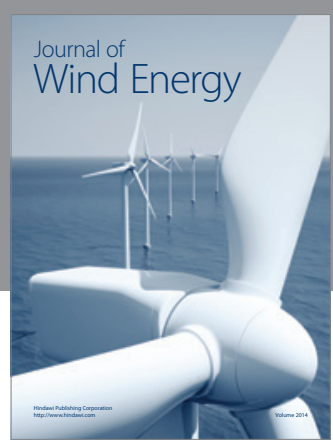

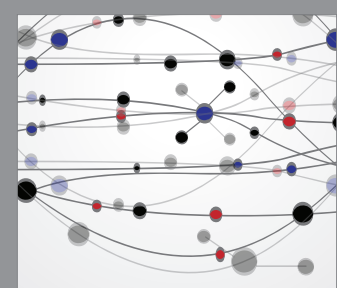

The Scientific World Journal

Submit your manuscripts at http://www.hindawi.com

Journal of

Structures
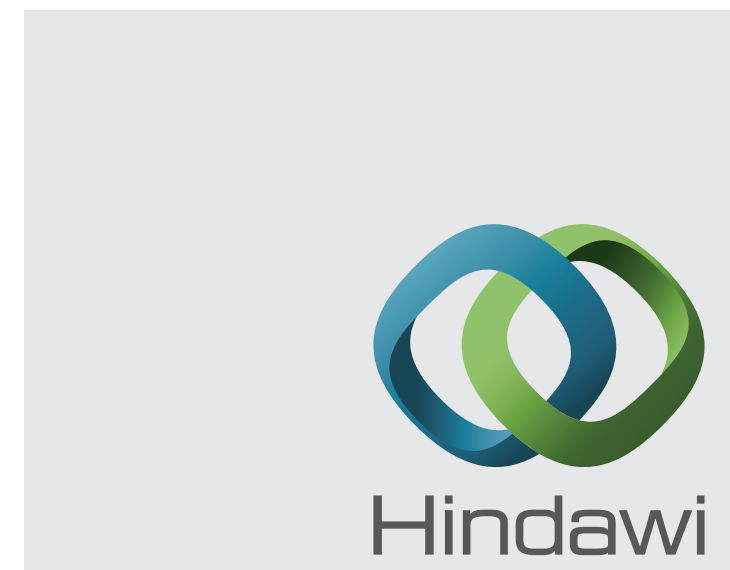

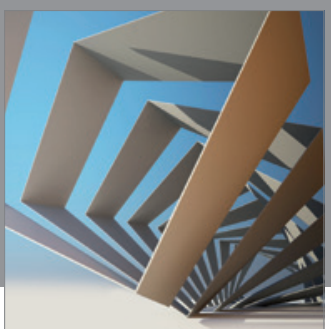

Rotating

Machinery
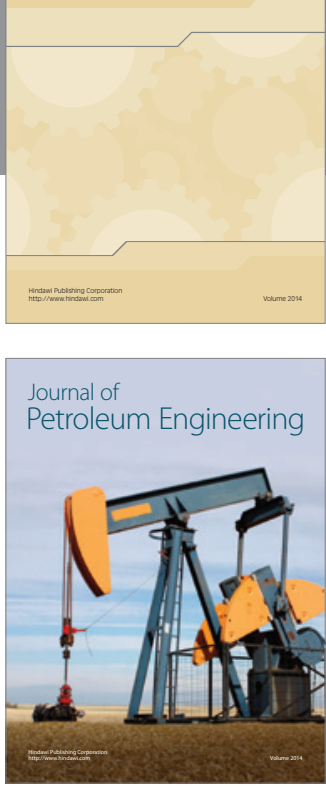

Journal of

Solar Energy
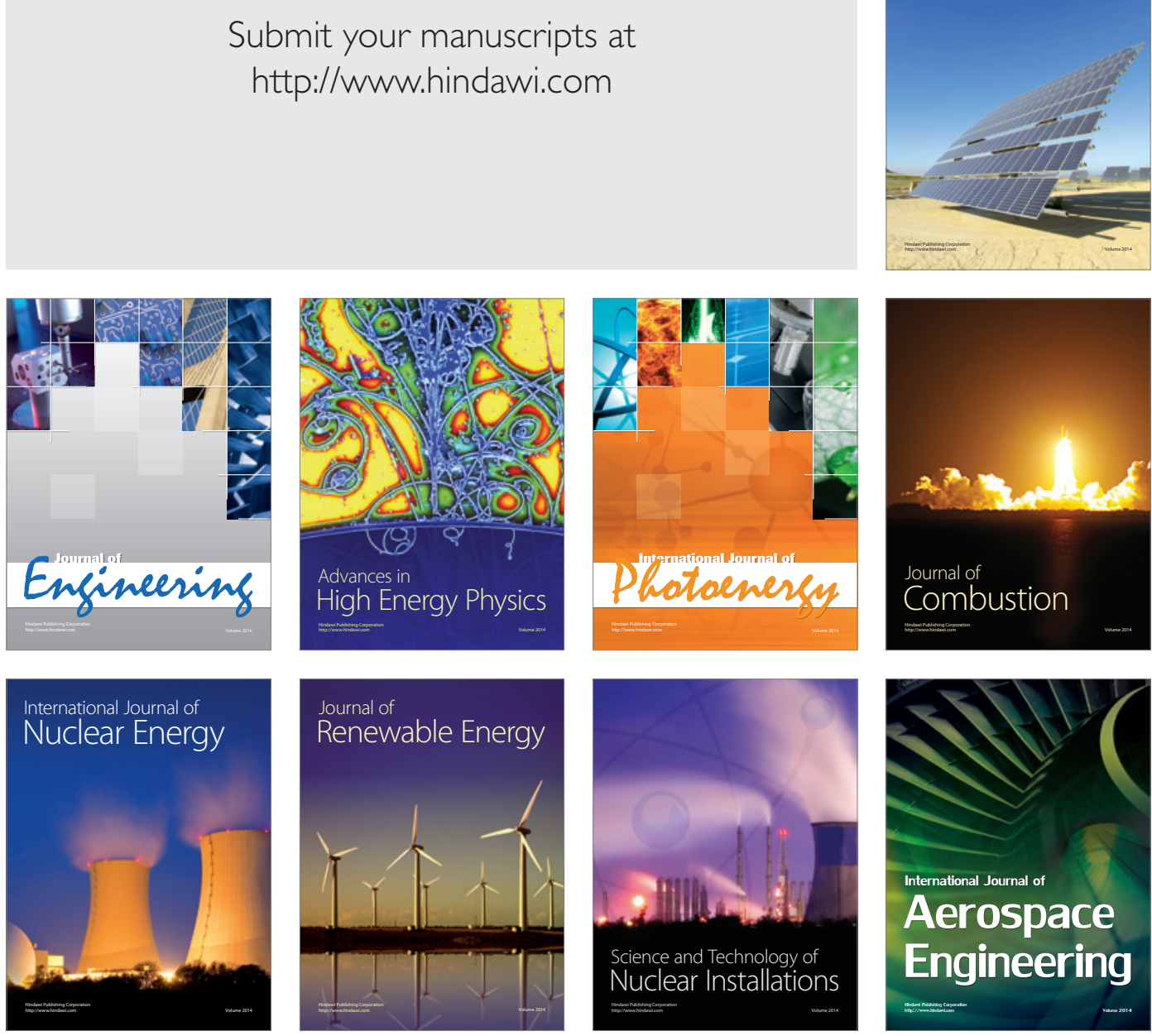